\title{
Genetic basis to hybrid inviability is more complex than hybrid male sterility in Caenorhabditis nematodes
}

\author{
Joanna D. Bundus ${ }^{1} \cdot$ Donglin Wang ${ }^{1} \cdot$ Asher D. Cutter $^{1}$ \\ Received: 19 October 2017 / Revised: 22 January 2018 / Accepted: 11 February 2018 / Published online: 7 April 2018 \\ (c) The Genetics Society 2018
}

\begin{abstract}
Hybrid male sterility often evolves before female sterility or inviability of hybrids, implying that the accumulation of divergence between separated lineages should lead hybrid male sterility to have a more polygenic basis. However, experimental evidence is mixed. Here, we use the nematodes Caenorhabditis remanei and $C$. latens to characterize the underlying genetic basis of asymmetric hybrid male sterility and hybrid inviability. We demonstrate that hybrid male sterility is consistent with a simple genetic basis, involving a single $\mathrm{X}$-autosome incompatibility. We also show that hybrid inviability involves more genomic compartments, involving diverse nuclear-nuclear incompatibilities, a mito-nuclear incompatibility, and maternal effects. These findings demonstrate that male sensitivity to genetic perturbation may be genetically simple compared to hybrid inviability in Caenorhabditis and motivates tests of generality for the genetic architecture of hybrid incompatibility across the breadth of phylogeny.
\end{abstract}

\section{Introduction}

Genetically intrinsic reproductive isolation evolves by the accumulation of incompatibilities between diverging populations (Bateson 1909; Dobzhansky 1937; Muller 1942). Although both intrinsic and extrinsic barriers can act at any time in the life cycle of an organism (Coyne 1992; Schluter 1998; Price and Bouvier 2002; Ramsey et al. 2003), intrinsic reproductive barriers are particularly important because they act to make speciation irreversible (Muller 1942). Consequently, much research aims to understand the genetic architecture underlying intrinsic hybrid sterility and inviability. In many systems, hybrid sterility evolves before hybrid inviability (Wu 1992; Moyle et al. 2004; Presgraves 2010; Turissini et al. 2017). Among the open questions related to the genetic architecture of hybrid incompatibilities, one key issue is whether barriers

Electronic supplementary material The online version of this article (https://doi.org/10.1038/s41437-018-0069-y) contains supplementary material, which is available to authorized users.

Asher D. Cutter

asher.cutter@utoronto.ca

1 Department of Ecology and Evolutionary Biology, University of Toronto, Toronto, ON M5S 3B2, Canada that evolve earlier will correspondingly accumulate more underlying genetic incompatibilities per unit time to make them genetically more complex.

As divergence between species accrues in the genome to include more loci, the number of potentially incompatible interactions increases geometrically, or "snowballs," increasing at least as fast as the square of the number of substitutions. If the incompatibility involves more than two loci, this increase should happen even faster. Three-way incompatibilities, for example, should increase as fast as the cube of the number of substitutions (Orr 1995; Orr and Turelli 2001), though diminishing returns incompatibility effects, for example, because of antagonistic interactions between Dobzhansky-Muller incompatibilities (DMIs), would counteract such "snowballing" (Kalirad and Azevedo 2017; Guerrero et al. 2017). This gives us one way of conceiving the genetic complexity of reproductive isolation between a pair of species: the total number of such DMIs. However, there are at least three other ways of defining the genetic complexity of reproductive isolation. DMIs themselves can vary in complexity, so we could also define the genetic complexity of reproductive isolation in terms of how many loci are involved in creating each DMI. Whether DMIs represent two-locus incompatibilities versus threeway or higher-order interactions, that is, the DMI network size, is often what speciation geneticists refer to when talking about the genetic complexity of reproductive 
isolation (Presgraves 2010). Another overall metric of the complexity of reproductive isolation is the total number of DMIs times DMI network size, that is, the total number of loci involved in DMIs. This definition that emphasizes the number of distinct genomic regions provides another common view by speciation genetics about the genetic complexity of reproductive isolation (Coyne and Orr 2004). The genomic compartmentalization of DMIs within and between autosomes versus sex chromosomes versus cytoplasmic genomes is a further component of the complexity of reproductive isolation in the genome. Characterizing genomic compartmentalization also provides a lower bound estimate of the number of independent genomic regions that contribute to reproductive isolation. This study quantifies the extent of genomic compartmentalization of incompatibilities that lead to reproductive isolation from hybrid sterility and inviability.

Hybrid male sterility could evolve especially quickly because of two processes. First, male reproductive traits and the genes underlying them might generally evolve more rapidly due to sexual selection or mutation biases ("faster males"), and therefore accumulate more substitutions as lineages diverge that could then contribute to DMIs (Wu and Davis 1993). Alternatively, male reproductive traits could be uniquely sensitive to perturbation, and therefore a greater fraction of substitutions that do accumulate between diverging lineages could contribute to incompatibilities ("fragile males") (Wu and Davis 1993). In this case, male and female reproductive traits might accumulate substitutions at the same rate, but more incompatibilities would affect male reproductive traits than female reproductive traits (Wu and Davis 1993). Both the faster male and fragile male hypotheses predict that the underlying genetic complexity of hybrid male sterility should exceed the complexity of barriers that evolve later (i.e., hybrid female sterility and hybrid inviability) in terms of the number of loci that contribute to reproductive isolation. This pattern holds true in Drosophila fruit flies (True et al. 1996; Hollocher and Wu 1996; Sawamura et al. 2000; Presgraves 2003; Tao et al. 2003) and Anopheles mosquitoes (Slotman et al. 2005), but not in Solanum tomatoes (Moyle and Nakazato 2008) or Tigriopus copepods (Willett 2008). How general it is across taxa that hybrid male sterility evolves before hybrid inviability and whether this corresponds to greater underlying genetic complexity, however, remains unknown.

Another common outcome is asymmetry between reciprocal crosses for hybrid sterility and inviability ("Darwin's corollary to Haldane's rule"), with one of the cross directions showing a stronger effect across a wide range of taxa from fish (Bolnick et al. 2005) and mammals (Good et al. 2008) to insects (Coyne and Orr 1989; Presgraves 2002) and nematodes (Woodruff et al. 2010) to plants (Scopece et al. 2007) and fungi (Dettman et al. 2003). Theory predicts asymmetric reproductive isolation to occur when incompatibilities involve uniparentally inherited elements: sex chromosomes, mitochondria, or maternally/paternally inherited epigenetic factors (Turelli and Moyle 2007). Because asymmetric reproductive isolation is so prevalent, at least one of these uniparentally inherited elements might be especially prone to involvement in reproductive isolation. Indeed, the $\mathrm{X}$-chromosome contributes so disproportionately to hybrid male sterility in diverse organisms that this pattern is termed the "large-X effect" (Coyne 1985; Presgraves 2008). It remains to be established, however, whether X-linked incompatibilities also disproportionately induce asymmetric hybrid inviability or whether other uniparentally inherited elements might more often be involved in hybrid inviability to yield Darwin's corollary to Haldane's rule. Moreover, many interspecies crosses yield $\mathrm{F}_{2}$ hybrid breakdown (Burton 1990; Breeuwer and Werren 1995; Li et al. 1997; Oka et al. 2004; Dey et al. 2014), which often involves recessive incompatibilities that are exposed as they are made homozygous. It has often been difficult to examine the underlying genetic basis, however, because so few systems produce fertile $F_{1}$ offspring with sufficient experimental tractability to perform large-scale crossing experiments to reveal the genetic contributions to both hybrid inviability and hybrid sterility.

In this study, we characterize the genetic complexity of asymmetric $F_{1}$ male sterility and $F_{2}$ hybrid inviability in a pair of gonochoristic Caenorhabditis species discovered recently to be partially reproductively isolated (Dey et al. 2012, 2014). Caenorhabditis remanei collections originate from across the temperate Northern hemisphere, whereas C. latens appears to have a narrower geographic range in China (Dey et al. 2012; Félix et al. 2014; Cutter 2015). These sister species are thought to have diverged from one another approximately $5.0 \mathrm{Mya}$ (given $K_{\mathrm{s}}=0.168$, $\mu=2.7 \times 10^{-9}, 10$ generations per year; Denver et al. 2009; Dey et al. 2012). In the lab, these species exhibit no obvious pre-mating isolation and, when crossed, $\mathrm{F}_{1}$ hybrids show reduced but still relatively high viability. However, $\sim 95 \%$ of the $\mathrm{F}_{1}$ males produced from crossing $C$. remanei females to $C$. latens males are sterile due to defects in gonad morphogenesis, despite nearly all the $F_{1}$ males from the reciprocal cross being fertile (Dey et al. 2014). Hybrid inviability is severe in the $F_{2}$ generation from both directions of the cross, with only $20-25 \%$ of $\mathrm{F}_{2}$ hybrid offspring hatching successfully (Dey et al. 2014). The proportion of embryos that become inviable at each developmental stage within embryogenesis differs depending on the initial direction of the $F_{1}$ cross (Dey et al. 2014). The combination of inviability at different stages of embryonic development, and variation in the proportion of hybrids becoming inviable depending on grandparent genotypes, hints at the 


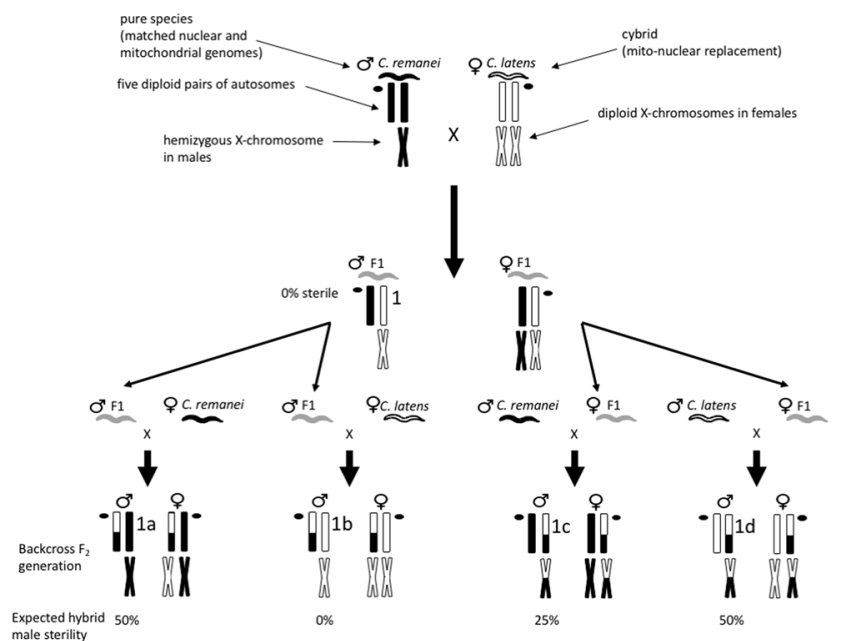

Fig. 1 Reciprocal $F_{1}$ backcross design, which produced 20 unique genotypes: four $F_{1}$ (two male and two female), and $16 F_{1}$ backcross genotypes. First, we crossed $C$. remanei (black fill) and $C$. latens (white fill) in both directions. In the initial $F_{1}$ cross "cybrid" strains with the mitochondrial DNA introgressed from one species into nuclear genotype of the other species were used to control for mitochondrial effects. We backcrossed $F_{1}$ males and females produced from both directions of the cross to both pure species (eight crosses total). Here, we show that one recombination event will lead to, on

possibility that hybrid inviability involves multiple distinct incompatibilities.

Here, we use reciprocal $F_{1}$ backcrosses to compare the genetic complexity of hybrid inviability and asymmetric hybrid male sterility in terms of the combinations of genomic compartments involved in hybrid dysfunction. We found that hybrid male sterility appears genetically simple compared to hybrid inviability in that it involves loci linked to fewer genomic compartments (X-chromosome, autosomes, mitochondria). A two-locus X-by-autosome interaction can largely explain patterns of hybrid male sterility, whereas hybrid inviability involves a combination of nuclear-nuclear, mito-nuclear, and parental effect incompatibilities. The relative genetic simplicity of hybrid male sterility compared to hybrid inviability implies that hybrid male sterility may not always evolve first or faster than hybrid inviability, even in systems with separate male and female sexes.

\section{METHODS}

\section{Nematode strains and rearing}

In order to determine the genetic basis of the asymmetric postzygotic isolation for viability and sterility seen in $C$. remane $\times C$. latens hybrids, we performed crosses using isofemale $C$. remanei strain PB219 and C. latens strain VX0088. To quantify the effect of mito-nuclear interactions

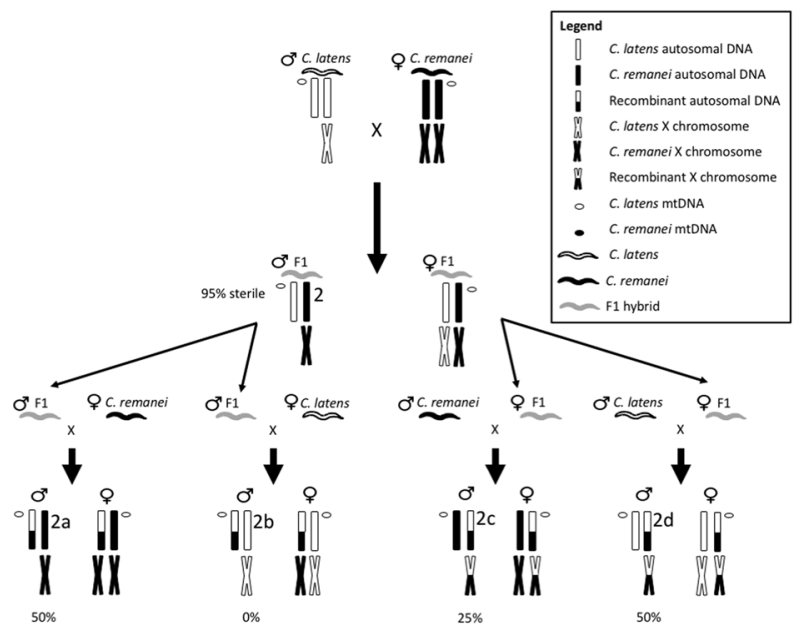

average, $50 \%$ of each species DNA being inherited from an $F_{1}$ hybrid parent. In any one individual, the proportion of DNA from each parent species will vary, because recombination can happen anywhere along the chromosome. We indicate the five pairs of autosomes with just a single chromosome pair in the diagram (vertical segments) in addition to mitochondria and the diploid X-chromosome (hemizygous in males). We measured the hatch rate and egg-to-adult survival of the progeny from all crosses, as well as hybrid male fertility

on hybrid viability and fertility, we created two cytonuclear hybrid "cybrid" strains. Mitochondrial DNA (mtDNA) is maternally inherited in Caenorhabditis, so by crossing $C$. latens females to $C$. remanei, and then backcrossing the $\mathrm{F}_{1}$ females to $C$. remanei males for 20 generations, we created a strain that has a $C$. remanei nuclear genome with $C$. latens mtDNA (strain VX0221). We performed the reciprocal cross in order to create a strain that has a $C$. latens nuclear genome with $C$. remanei mtDNA (strain VX0219).

We cultured, maintainedand crossed worms at $25^{\circ} \mathrm{C}$ on Petri dishes containing NGM-Lite agar media seeded with Escherichia coli strain OP50 as food. To remove fungal and bacterial contamination before crosses, we cleaned strains using a standard bleaching protocol (Stiernagle 1999). We performed all crosses on $35-\mathrm{mm}$ plates with a single $\sim 10 \mathrm{~mm}$ diameter bacterial spot.

\section{Effect of mito-nuclear incompatibilities on hybrid viability and hybrid sterility}

In order to isolate the effect that mito-nuclear incompatibilities have on hybrid inviability seen in $C$. remanei $\times C$. latens hybrids, we created two new mito-nuclear hybrid strains (VX0219 and VX0221), and performed intra-strain crosses to compare these cybrids to pure species strains $(C$. latens strain VX0088 and C. remanei strain PB219). For each cross, we picked virgin females at the L4 stage (fourth and final larval stage), and allowed them to develop into adults overnight. We mated individual adult females to 
three adult males. After $18 \mathrm{~h}$ of mating, we sacrificed the males and transferred females to a new plate each day until egg laying ceased. We counted the total number of fertilized eggs laid, and the total number of eggs that remained unhatched after $\sim 18 \mathrm{~h}$ as a measure of embryonic inviability; a standard C. elegans egg-hatching assay (Dey et al. 2014). Progeny were allowed to grow until adulthood, after which they were transferred to $4{ }^{\circ} \mathrm{C}$ to halt development for scoring. We then counted the total number of surviving adult progeny. We analyzed the total number of eggs laid and total adult offspring, and survival data with one-way analysis of variance implemented in $R$ (R Core Team 2016).

To quantify the effect that mito-nuclear incompatibilities have on the fertility of $\mathrm{F}_{1}$ hybrid males produced when $C$. latens males are crossed to $C$. remanei females, we used the same four cybrid and pure species strains, and crossed them to each other and to themselves in all 16 reciprocal combinations. To quantify hybrid male fertility, we picked adult males into M9 media to clear their guts of bacteria and make visualizing the gonads easier. As a measure of male sterility, we examined gonad morphology to identify defects in gonad formation that prevent males from transferring sperm (Dey et al. 2014). After $\sim 12 \mathrm{~h}$ in M9, we placed 10 males at a time onto a microscope slide prepared with a 20 $\mu \mathrm{L}$ drop of sodium azide $\left(\mathrm{NaN}_{3}\right)$ solution, which paralyzes worms making the gonads easier to visualize using differential interference contrast (DIC) microscopy $(\times 60$ magnification).

\section{$F_{1}$ backcrosses}

We used $F_{1}$ backcrosses to gain insight into the genetic basis of hybrid inviability and sterility in $C$. remanei $\times C$. latens hybrids. Our reciprocal backcrossing design (Fig. 1) allowed us to quantify hybrid inviability and sterility in hybrids that have, on average, different proportions of both the $\mathrm{X}$-chromosomes and autosomal chromosomes from each of the parent species. We were also able to examine the effect of some recessive incompatibilities, as these were exposed when they were made homozygous in individuals of certain backcross genotypes. However, we were not able to examine the effect of autosomal recessive-by-recessive incompatibilities, which are present in $\mathrm{F}_{2}$ hybrids, but not in our experimental $F_{1}$ hybrid backcross individuals. Finally, because we performed reciprocal crosses and controlled for mitochondrial background, we were able to test for parental effects on reproductive isolation. With the exception of crosses involving $\mathrm{F}_{1}$ males produced from $C$. latens males mated to $C$. remanei females, we picked virgin females at the L4 stage, and allowed them to develop into adults overnight. We mated individual adult females to three males. After $18 \mathrm{~h}$ of mating we sacrificed the males and females, and counted the total number of fertilized eggs laid. After another $\sim 18 \mathrm{~h}$, we counted the total number of eggs that remained unhatched to quantify embryonic viability.

Approximately $95 \%$ of $\mathrm{F}_{1}$ males produced by crossing $C$. remanei females and $C$. latens males are sterile (Dey et al. 2014). For crosses involving these males, we used bulk mating arenas of 20 females to 40 males to allow more efficient fertilization by the few fertile males. This difference in mating design did not need to be accounted for in the statistics because total egg number were not used. After $18 \mathrm{~h}$ of mating, we transferred mated females to a new plate and allowed them to lay eggs, and after $18 \mathrm{~h}$, we sacrificed the females and counted the total number of fertilized eggs. We then quantified embryonic viability by counting the number of unhatched eggs remaining after a further $\sim 18 \mathrm{~h}$.

For all crosses, progeny were allowed to grow until adulthood and then were transferred to $4{ }^{\circ} \mathrm{C}$ to halt growth to facilitate scoring of the total number of adult male and female progeny individuals. To measure hybrid male fertility, we examined adult male gonad morphology to identify defects in gonad formation using DIC microscopy (Dey et al. 2014).

We used generalized linear mixed-effects models implemented in $R$ (R Core Team 2016), using the lme4 package (Bates et al. 2015) to determine whether hatch rate and L1-to-adult survival of $F_{1}$ backcross progeny is influenced by: the direction of the initial $F_{1}$ cross, the sex of the $\mathrm{F}_{1}$ hybrid used in the backcross, and the species to which the $F_{1}$ hybrid was backcrossed. We treated both hatch rate and L1-to-adult survival as binomial responses, with an individual-level random effect to account for overdispersion. We tested the effects using a Wald $Z$ test.

\section{Estimating effects of $\mathbf{G} \times \mathbf{G}$ incompatibilities}

Each of the interspecific and $F_{1}$ backcrosses produces individuals with different, but on average predictable genotypes based on the direction of the cross and the sex of this individual. We used a model to determine which combination of genetic-by-genetic $(G \times G)$ incompatibilities can best describe the pattern of male and female hybrid inviability seen across all cross combinations. To do this, we first calculated the sex-specific hatch rates and L1-to-adult survival rates for each cross direction based on the mean hatch rate for that cross direction, the L1-to-adult survival rate for that cross direction and the known adult sex ratio for that cross direction. In every case, we assumed that the sex ratio at fertilization was 50:50.

Although we lack complete genetic information for a given individual, we can nevertheless calculate the probability that a particular autosome-by-autosome, X-X, autosome-X, autosome-mitochondrial, or X-mitochondrial incompatibility will be exposed in that genotype for males 
Table 1 All $\mathrm{G} \times \mathrm{G}$ incompatibility classes revealed in $\mathrm{F}_{1}$ and $\mathrm{F}_{1}$ backcross hybrids, and their predicted fitness effect when exposed in hybrid animals

\begin{tabular}{|c|c|c|c|c|c|c|c|c|c|}
\hline \multirow[t]{2}{*}{ Incompatibility class } & \multicolumn{3}{|c|}{ Fitness effect egg-to-adult ${ }^{\mathrm{a}}$} & \multicolumn{3}{|c|}{ Fitness effect egg-to-L1 ${ }^{\mathrm{a}}$} & \multicolumn{3}{|c|}{ Fitness effect L1-to-adult ${ }^{\mathrm{a}}$} \\
\hline & Exclude mt & Rec. mt & Dom. mt & Exclude mt & Rec. mt & Dom. mt & Exclude mt & Rec. $\mathrm{mt}$ & Dom. $\mathrm{mt}$ \\
\hline $\mathrm{A}_{\text {lat,dom }}-\mathrm{A}_{\text {rem,dom }}$ & 0 & 0 & 0 & 0 & 0 & 0 & 0 & 0 & 0 \\
\hline $\mathrm{A}_{\mathrm{lat}, \mathrm{dom}}-\mathrm{A}_{\mathrm{rem}, \mathrm{rec}}$ & 0.63 & 0.67 & 1 & 0 & 0 & 0 & 0.63 & 0.64 & 0.70 \\
\hline $\mathrm{A}_{\text {lat,rec }}-\mathrm{A}_{\text {rem,dom }}$ & 0 & 0 & 0 & 0.55 & 0 & 0 & 0 & 0 & 0 \\
\hline $\mathrm{A}_{\text {lat,dom }}-\mathrm{X}_{\mathrm{rem}, \mathrm{dom}}$ & 0 & 0 & 0 & 0 & 0 & 0 & 0 & 0 & 0 \\
\hline $\mathrm{A}_{\text {rem,dom }}-X_{\text {lat,dom }}$ & 1 & 0.49 & 0 & 0 & 0 & 0 & 0 & 0 & 0 \\
\hline $\mathrm{A}_{\text {lat,dom }}-\mathrm{X}_{\mathrm{rem}, \mathrm{rec}}$ & 0.57 & 0.72 & 0.70 & 0.39 & 0.38 & 0.37 & 0.55 & 0.56 & 0 \\
\hline $\mathrm{A}_{\text {rem,dom }}-X_{\text {lat,rec }}$ & 0.72 & 0 & 0.74 & 0.44 & 0.38 & 0.32 & 0 & 0 & 0 \\
\hline $\mathrm{A}_{\text {lat,rec }}-\mathrm{X}_{\text {rem,dom }}$ & 0 & 0 & 0 & 0 & 0 & 0 & 0 & 0 & 0 \\
\hline $\mathrm{A}_{\text {rem,rec }}-X_{\text {lat,dom }}$ & 1 & 1 & 1 & 1 & 1 & 1 & 1 & 1 & 1 \\
\hline $\mathrm{A}_{\text {lat,rec }}-\mathrm{X}_{\mathrm{rem}, \mathrm{rec}}$ & 0 & 0 & 0 & 0 & 0 & 0.62 & 0 & 0 & 0 \\
\hline$A_{\text {rem,rec }}-X_{\text {lat,rec }}$ & 0 & 1 & 0.92 & 0 & 0 & 0 & 1 & 1 & 1 \\
\hline $\mathrm{X}_{\text {lat,dom }}-\mathrm{X}_{\text {rem,dom }}$ & 0 & 0 & 0 & 0 & 0 & 0 & 0 & 0 & 0 \\
\hline $\mathrm{X}_{\text {lat,dom }}-\mathrm{X}_{\text {rem,rec }}$ & 1 & 1 & 1 & 1 & 1 & 1 & 0.92 & 0.92 & 1 \\
\hline$X_{\text {lat,rec }}-X_{\text {rem,dom }}$ & 1 & 1 & 1 & 0 & 0 & 0 & 0 & 0 & 0 \\
\hline$X_{\text {lat,rec }}-X_{\text {rem,rec }}$ & 0 & 0 & 0 & 0 & 0 & 0 & 0 & 0 & 0 \\
\hline $\mathrm{Mt}_{\text {lat }}-\mathrm{A}_{\mathrm{rem}, \mathrm{dom}}$ & - & - & 0 & - & - & 0 & - & - & 0.44 \\
\hline $\mathrm{Mt}_{\mathrm{rem}}-\mathrm{A}_{\mathrm{lat}, \mathrm{dom}}$ & - & - & 0 & - & - & 0 & - & - & 0 \\
\hline $\mathrm{Mt}_{\text {lat }}-\mathrm{X}_{\mathrm{rem}, \mathrm{dom}}$ & - & - & 0 & - & - & 0 & - & - & 0 \\
\hline $\mathrm{Mt}_{\mathrm{rem}}-\mathrm{X}_{\text {lat,dom }}$ & - & - & 0 & - & - & 0.29 & - & - & 0 \\
\hline $\mathrm{Mt}_{\mathrm{lat}}-\mathrm{A}_{\mathrm{rem}, \mathrm{rec}}$ & - & 0 & - & - & 0 & - & - & 0 & - \\
\hline $\mathrm{Mt}_{\mathrm{rem}}-\mathrm{A}_{\text {lat,rec }}$ & - & 0.62 & - & - & 0.72 & - & - & 0 & - \\
\hline $\mathrm{Mt}_{\text {lat }}-\mathrm{X}_{\text {rem,rec }}$ & - & 0 & - & - & 0 & - & - & 0 & - \\
\hline $\mathrm{Mt}_{\mathrm{rem}}-\mathrm{X}_{\mathrm{lat}, \mathrm{rec}}$ & - & 0 & - & - & 0 & - & - & 0 & - \\
\hline Sum of squared deviations & 0.41 & 0.42 & 0.40 & 0.66 & 0.47 & 0.47 & 1.78 & 1.78 & 1.44 \\
\hline
\end{tabular}

${ }^{a}$ All effects $>0$ are significantly different from 0

$A$ autosome, $X X$-chromosome, Mtmitochondria, rem C. remanei, lat C. latens, rec recessive, dom dominant

and females produced in each cross. Additionally, we have information about the probability of whether a dominantby-dominant, dominant-by-recessive, or recessive-byrecessive incompatibility will be exposed. We presumed no co-dominance, and that all inviability incompatibilities affect both males and females, which appears to be the case in other systems (Orr 1999). In total, there are 23 possible $\mathrm{G} \times \mathrm{G}$ incompatibility types that could contribute to hybrid inviability (Table 1). Because our experimental design produces only 20 genotype classes, it does not give us the power to assess all 23 incompatibility types in the same model. Instead, we ran three separate models: one model included only autosomal and X-linked incompatibilities (15 incompatibilities total), one model included the autosomal and $\mathrm{X}$-linked incompatibilities plus recessive mito-nuclear incompatibilities (19 incompatibilities), and the final model included autosomal, $\mathrm{X}$, and dominant mito-nuclear incompatibilities (19 incompatibilities) (Table 1). We determined the probability that each of these incompatibility types could act in males and female offspring produced from each of the 10 crosses that we assayed (all $F_{1}$ crosses and backcrosses, 20 genotypes in total) (Supplemental Table 1). Using the probabilities of each of the incompatibilities being exposed in a given offspring genotype class, we estimated the additive combination of fitness effects of each of the incompatibilities that together best explained the observed patterns of hybrid inviability.

We searched for fitness effects of each of the incompatibility types that best explain the overall observed fitness of each genotype class using the optim function in $R$ ( $\mathrm{R}$ Core Team 2016). We used random starting values between 0 and 1 for the fitness effect of each incompatibility ( 0 meaning there is no fitness effect, 1 meaning complete inviability), and applied the Nelder-Mead algorithm for iterating until improvements in the minimum sum of squared deviations became small $(<0.1)$. We conducted 10,000 repeated optimizations using different random starting values to ensure the best parameters were obtained. 
Table 2 All possible $\mathrm{G} \times \mathrm{G}$ incompatibility classes, and their effects on hybrid male sterility

\begin{tabular}{ll}
\hline $\begin{array}{l}\text { Incompatibility } \\
\text { class }\end{array}$ & $\begin{array}{l}\text { Fitness } \\
\text { effect on } \\
\text { hybrid } \\
\text { male } \\
\text { sterility }\end{array}$ \\
\hline $\mathrm{A}_{\text {lat,dom}}-\mathrm{A}_{\text {rem,dom }}$ & 0 \\
$\mathrm{~A}_{\text {lat,dom }}-\mathrm{A}_{\text {rem,rec }}$ & 0 \\
$\mathrm{~A}_{\text {lat,rec }}-\mathrm{A}_{\text {rem,dom }}$ & $0.15^{\mathrm{a}}$ \\
$\mathrm{A}_{\text {lat,dom}}-\mathrm{X}_{\text {rem }}$ & $0.86^{\mathrm{b}}$ \\
$\mathrm{A}_{\text {rem,dom }}-\mathrm{X}_{\text {lat }}$ & $0.08^{\mathrm{a}}$ \\
$\mathrm{A}_{\text {lat,rec }}-\mathrm{X}_{\text {rem }}$ & 0 \\
$\mathrm{~A}_{\text {rem,rec }}-\mathrm{X}_{\text {lat }}$ & $1.00^{\mathrm{b}}$ \\
$\mathrm{X}_{\text {lat }}-\mathrm{X}_{\text {rem }}$ & 0 \\
Sum of squared & 0.05 \\
deviations & \\
\hline
\end{tabular}

${ }^{a}$ Not significantly different from 0

${ }^{\mathrm{b}}$ Significantly different from 0

$A$ autosome, $X X$-chromosome, $M t$ mitochondria, rem C. remanei, lat C. latens, rec recessive, dom dominant

We simplified the model by successively removing the incompatibility with the smallest effect size from the model until only those incompatibilities with a significant effect, as determined by comparing models with $\mathrm{F}$ tests, remained. The runs with the smallest sums of squares all converged on similar parameter values.

We used the same method to determine which $G \times G$ incompatibilities best explain the patterns of hybrid male sterility. Because there is only one X-chromosome present in hybrid males, we were able to disregard the dominance of any incompatibilities involving the X-chromosome. We were also able to disregard the mitochondrial genotype based on the results of our crosses which showed that mitonuclear incompatibilities do not contribute to hybrid male sterility (see below and Supplemental Fig. 1). Therefore, we examined the contribution of eight incompatibility types to hybrid male sterility (Table 2 ).

\section{RESULTS}

\section{Mito-nuclear incompatibilities contribute to reduced hybrid offspring production, but not hybrid male gonad defects}

To determine whether mito-nuclear incompatibilities contribute to inviability or sterility in $C$. latens $\times C$. remanei hybrids, we compared the lifetime reproductive output of pure strains to the reproductive output of mitochondrial replacement strains that had either the $C$. remanei
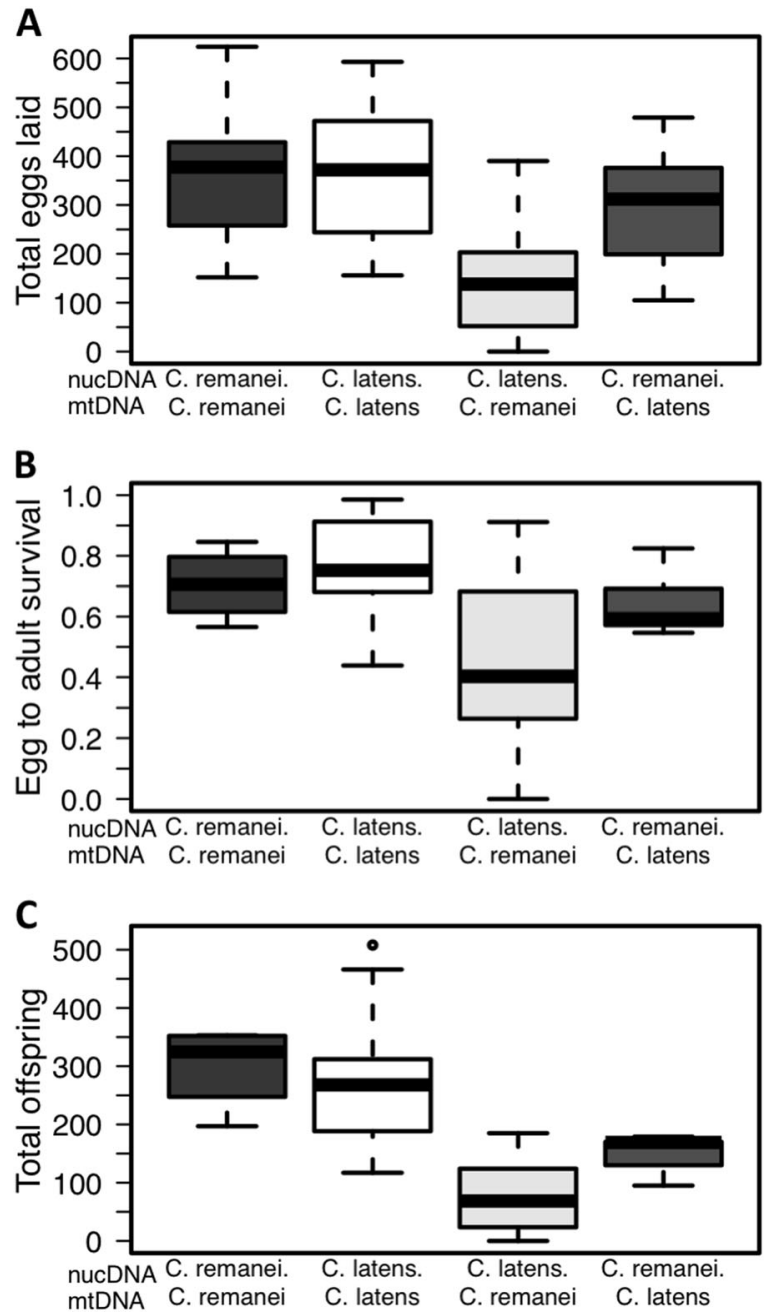

Fig. 2 a Total eggs, b egg-to-adult survival, and c total offspring produced by pure $C$. remanei and $C$. latens, and mito-nuclear replacement strains. Both mito-nuclear replacement strains produce significantly fewer total offspring than pure species $(C$. latens with $C$. remanei mt.; $C$. remanei with $C$. latens $\mathrm{mt}$.). $N=6-30$ replicates per cross

mitochondrial genome in a $C$. latens nuclear background or the $C$. latens mitochondrial genome in a $C$. remanei nuclear background. These cytoplasmic hybrid ("cybrid") strains were created from 20 generations of backcrossing. We found that the strain has an effect on the total adult offspring produced $\left(\mathrm{F}_{3,49}=26.03, P<0.001\right)$. We observed no difference in the total number of adult offspring produced between pure $C$. latens and pure $C$. remanei, but both of the mitochondrial replacement strains produced fewer adult offspring than the pure species $(C$. latens nuclear with $C$. remanei mitochondria Tukey's honest significant difference (HSD), $P<0.0001, C$. remanei nuclear with C. latens mitochondria Tukey's HSD, $P=0.02$ ) (Fig. 2). This difference in total offspring results from a combination of fewer eggs laid depending on strain $\left(\mathrm{F}_{2,94}=17.98, P<\right.$ $0.0001)$ and lower egg-to-adult survival $\left(\mathrm{F}_{3,45}=4.38, P=\right.$ 
Table 3 Parameter estimates from a GLMM analysis of hybrid offspring produced from each of the eight $\mathrm{F}_{1}$ backcrosses

\begin{tabular}{|c|c|c|c|c|c|c|}
\hline \multirow[t]{2}{*}{ Effect } & \multicolumn{3}{|l|}{ Egg to L1 } & \multicolumn{3}{|l|}{ L1 to adult } \\
\hline & Coefficient & $Z$ & $P$ & Coefficient & $Z$ & $P$ \\
\hline Intercept & -0.6254 & & & -0.1089 & & \\
\hline $\begin{array}{l}\text { Initial direction of } \mathrm{F} 1 \text { cross (ID) ( } C \text {. } \\
\text { remanei females x } C \text {. latens males) }\end{array}$ & 1.9440 & 9.371 & $<0.0001$ & 0.2469 & 0.688 & 0.49 \\
\hline Backcross species (C. remanei) & -0.8646 & -4.019 & $<0.0001$ & -1.6181 & -3.852 & 0.0001 \\
\hline Hybrid sex (male) & 1.1403 & 4.765 & $<0.0001$ & 0.6646 & 1.511 & 0.13 \\
\hline ID $x$ backcross species & -0.2651 & -0.845 & 0.40 & 0.2426 & 0.482 & 0.62 \\
\hline ID $x$ hybrid sex & -0.6252 & -1.567 & 0.12 & -0.9061 & -1.473 & 0.14 \\
\hline Backcross species $\mathrm{x}$ hybrid sex & 1.2487 & 3.384 & 0.0007 & 1.0434 & 1.700 & 0.09 \\
\hline ID $\mathrm{x}$ backcross species $\mathrm{x}$ hybrid sex & 0.2328 & 0.403 & 0.69 & 0.3370 & 0.400 & 0.69 \\
\hline
\end{tabular}

Bold values indicate significant effect

0.009), although the only factor with an individually significant reduction occurs for the cybrid with $C$. latens nuclear DNA and $C$. remanei mitochondria (Tukey's HSD, $P<0.0001$ ).

We also examined whether mito-nuclear incompatibilities contribute to the asymmetric hybrid male sterility seen in this cross. To isolate mito-nuclear effects, we performed reciprocal crosses between the two pure species and the two mito-nuclear cybrid strains in all 16 reciprocal combinations, and examined the gonad morphology of males produced from each cross to infer male sterility $(\sim 50$ males per cross).

If mito-nuclear incompatibilities drive hybrid male sterility mediated by gonad defects, then we would expect that males with $C$. remanei $\mathrm{mtDNA}$ and $C$. latens nuclear DNA would have the highest rates of sterility. Our results were not consistent with this prediction: the genotype classes showing male gonad defects did not depend on mitochondrial genotype (Supplemental Fig. 1). Instead, the genetic combinations associated with male gonad defects suggested the possibility of a strong role for X-autosome incompatibility in causing hybrid male sterility (see below).

\section{Maternal effects contribute to $F_{1}$ backcross hybrid inviability}

To examine the underlying causes of inviability in $C$. remanei $\times C$. latens hybrids, we performed a reciprocal $F_{1}$ backcross (Fig. 1). This allowed us to examine the influence of both zygote genotype and of transgenerational (i.e., parental) effects on hybrid viability. In these crosses, we made use of cybrid strains. This controlled for mitochondrial background in order to draw stronger inferences about other maternally inherited factors (e.g., maternal provisioning of the oocyte). We modeled the effect of the initial direction of the $F_{1}$ cross, the direction of hybrid backcross, and the sex of the hybrid used in the backcross to explain variation in both hatch rate and L1-to-adult survival. We found that all three of these factors contribute to differences in hatch rate, and we also found a significant interaction between the species used in the backcross and the sex of the hybrid in the backcross (Table 3). By contrast, we found that only the species that the $F_{1}$ hybrid was backcrossed to exerts a significant influence on L1-to-adult survival (Table 3). Although several DMIs involving uniparentally inherited elements potentially underlie the effects on hybrid viability exerted by the initial direction of the interspecific cross and the direction of the $F_{1}$ backcross, the influence that hybrid sex has on viability can be explained most plausibly by parental effects. In this case, hybrid females always produce hybrid eggs less likely to hatch than do hybrid males, regardless of the initial $F_{1}$ cross or the species it is backcrossed to (Fig. 3), indicating a strong negative effect of having a hybrid mother.

\section{Many $\mathbf{G} \times \mathbf{G}$ incompatibilities needed to explain patterns of hybrid inviability}

Our reciprocal backcross design produced 20 distinct hybrid genotype classes (10 crosses, with males and females produced from each cross) (Fig. 1), and we found that multiple gene $\times$ gene $(G \times G)$ incompatibility types are required to explain the pattern of hybrid inviability seen across these hybrids (Table 1). To determine which combination of the distinguishable $\mathrm{G} \times \mathrm{G}$ incompatibility types best explain hybrid inviability across all genotypes, we created three maximum likelihood models in which each incompatibility type has a defined probability of being exposed in a given hybrid genotype class. The models then optimize the effect size of each incompatibility based on which combination of incompatibilities best explain the observed pattern of hybrid inviability across all genotype classes. We ran the model to 
Fig. 3 a Hatch rate survival for the initial $F_{1}$ cross and each of the eight reciprocal backcrosses. In each case, egg-to-L1 survival is lower when the hybrid female is backcrossed than when the hybrid male is backcrossed. b L1-to-adult survival for each cross (virtually all nonembryonic hybrid inviability occurs during the first larval (L1) stage of development). L1to-adult survival can appear to be greater than one because of developmental delays during embryogenesis, so eggs are counted as unhatched/inviable when they in fact hatch after assay counting. Whiskers and outlier points with values $>1.6$ have been excluded for visual clarity. c Proportion of males among adult hybrids. rem $C$. remanei, lat C. latens, hyb hybrid. Generally, patterns of hybrid inviability conform to Haldane's rule, with the exception of the offspring indicated by the second to the left box. In this cross, a strong incompatibility is revealed only in female offspring, causing Haldane's rule to be disobeyed
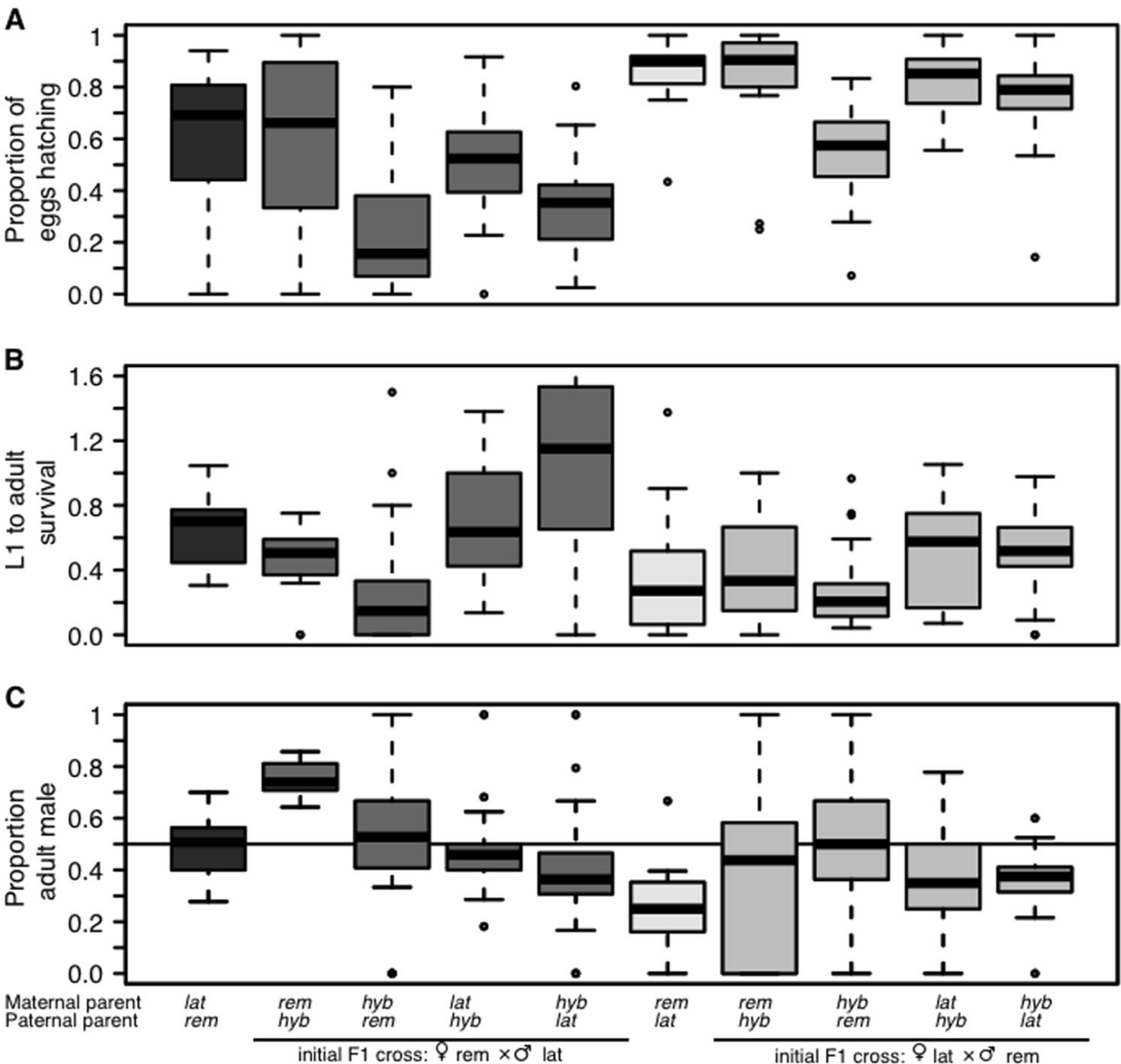

determine which $\mathrm{G} \times \mathrm{G}$ incompatibility types explain eggto-adult survival, hatch rate, and L1-to-adult survival.

We found that, depending on whether mito-nuclear incompatibilities are included, either seven or eight incompatibility types are required to explain patterns of egg-to-adult survival (five or six affect hatch rate, and five affect L1-to-adult survival) (Table 1). Although incompatibility types overlap between the developmental stages, several of the incompatibility types only affect one of the two stages of inviability. One particularly interesting incompatibility type that we identified is the $C$. remanei recessive autosome $\times C$. latens dominant $\mathrm{X}$-chromosome incompatibility. This incompatibility type is strong, and only gets exposed in three of the hybrid genotype classes produced in our backcross design. Because hybrid male sterility involves a $C$. latens dominant autosome $\times C$. remanei $\mathrm{X}$ incompatibility (discussed below), the $\mathrm{X}-\mathrm{A}$ incompatibility inducing inviability has the effect of making surviving males more likely to be sterile than we would have otherwise predicted. We also identified incompatibilities linked to both the $C$. remanei and $C$. latens mitochondria, consistent with our empirical data showing that mito-nuclear replacement strains produce fewer offspring (see above, Fig. 2).

\section{X-autosome incompatibility can explain hybrid male sterility}

To determine more directly the role of $\mathrm{X}$-autosome incompatibility in hybrid male sterility, we examined males produced from all directions of our reciprocal $F_{1}$ backcross (mean $\sim 88 /$ cross). These backcrosses each produce four nuclear genotype classes of males, each with a different average proportion of $\mathrm{X}$ and autosomal chromosomes expected to be inherited from the parent species (Fig. 1), to give us clear predictions for phenotypic effects under different causal genetic hypotheses.

If a two-locus $\mathrm{X}$-autosome incompatibility drives hybrid male sterility, then males with the highest average proportion of DNA from the $C$. remanei $\mathrm{X}$-chromosome in combination with $C$. latens autosomal DNA should have the greatest incidence of sterility (Fig. 4). By contrast, males expected to have a high proportion of $C$. latens $\mathrm{X}$ chromosome DNA coupled with $C$. remanei autosomal DNA should exhibit the lowest rates of male sterility. Our results from these backcrosses are generally consistent with these predictions (Fig. 4). Males that lack the $C$. remanei Xchromosome altogether are predicted to be fertile, and, indeed, we only rarely see sterility among such males (9\% 


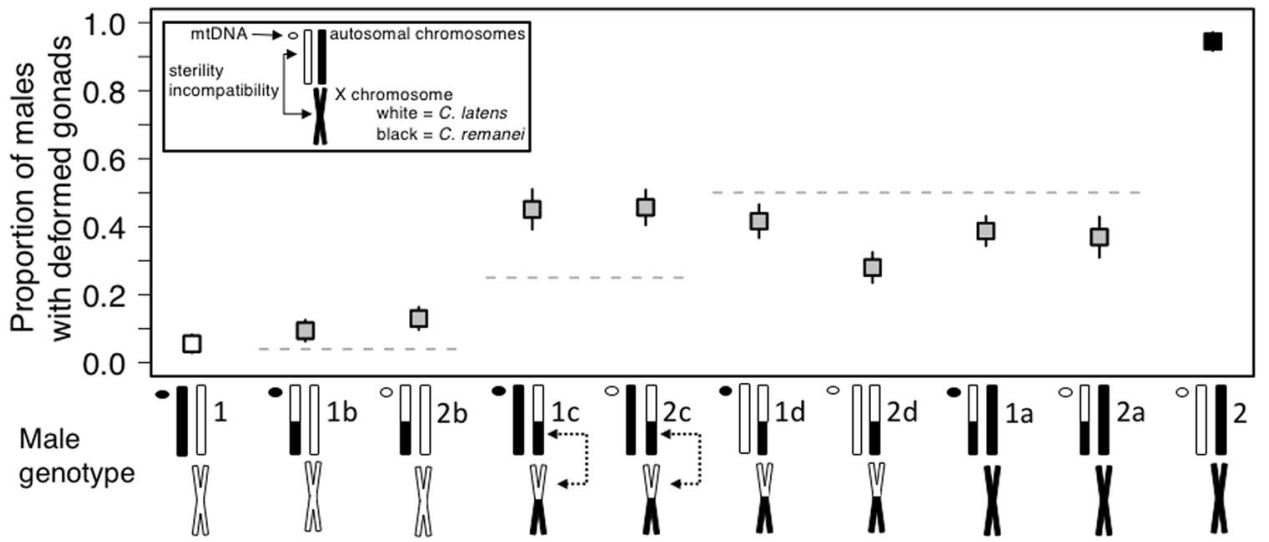

Fig. 4 Hybrid male sterility for $\mathrm{F}_{1}$ males produced by crossing $C$. remanei males to $C$. latens females (white fill, left) and $C$. latens males to $C$. remanei females (black fill, right), as well as for the eight male genotypes produced in $F_{1}$ backcrosses (equivalent nuclear genotypes indicated with the same letter). Male genotype diagrams as in Fig. 1 (C. remanei DNA in black, C. latens DNA in white). Predictions for the proportion of males from each cross direction that would be sterile given a simple two-way $C$. remanei $\mathrm{X}$-chromosome by $C$. latens autosomal dominant incompatibility are indicated by the dashed lines. Observed proportion of sterile males from each cross are indicated by squares $\pm 95 \%$ binomial confidence intervals. Dotted arrows indicate the large-effect $C$. latens $\mathrm{X}$-chromosome $\times C$. remanei recessive autosomal incompatibility for inviability. This incompatibility leads surviving males to have an increased probability of sterility and $12 \%$, although both are significantly higher than the expectation of $0 \%$ sterility (males $1 \mathrm{~b}$ and $2 \mathrm{~b}$ from Fig. $4, \chi^{2}$ $=6.427, P=0.011$ and $\chi^{2}=11.847, P=<0.001$, respectively). Two classes of males are predicted to have a $50 \%$ incidence of sterility, either because they always have the $C$. remanei $\mathrm{X}$-chromosome together with a $50 \%$ chance of inheriting the $C$. latens autosomal component of the incompatibility, or because they always have the $C$. latens autosomal component and a 50\% chance of inheriting the $C$. remanei $\mathrm{X}$-chromosome. We found that this class of males does have an intermediate incidence of sterility, 28\% (male $2 \mathrm{~d}$ from Fig. 4, significantly lower than our prediction, $\chi^{2}=$ 9.269, $P=0.002$ ) and $36-48 \%$ (males $1 \mathrm{~d} \chi^{2}=1.275$, $P=0.26$, 1a $\chi^{2}=2.761, P=0.097$ and 2a $\chi^{2}=1.999, P=$ 0.16 ), only slightly lower than our prediction (Fig. 4). The final genetic class of males are predicted to have a $25 \%$ incidence of sterility, because they have a $50 \%$ chance of inheriting the $C$. remanei $\mathrm{X}$-chromosome component of the incompatibility and a $50 \%$ chance of inheriting the $C$. latens autosomal component. In these males, we see more sterility than expected $\left(\sim 45 \%\right.$ instead of $25 \%$, male $1 \mathrm{c}: \chi^{2}=5.217$, $P=0.022$ and male $2 \mathrm{c} \chi^{2}=7.707, P=0.005$ ) (Fig. 4).

These differences from our simple predictions likely result from the influence other genetic interactions causing inviability that lead to surviving males being either more or less likely to be sterile than the simple predictions that neglect a role of inviability incompatibilities. For example, we detected a strong $C$. latens dominant $\mathrm{X}$-chromosome by $C$. remanei recessive autosomal incompatibility that is exposed in only the males expected to have a $25 \%$ incidence of sterility (Fig. 4, males $1 \mathrm{c}$ and $2 \mathrm{c}$ ). As a consequence of this strong incompatibility for inviability, surviving males have a $>50 \%$ chance of inheriting both the $C$. remanei $\mathrm{X}$-chromosome and the $C$. latens autosomal component of the sterility incompatibility, which explains the elevated incidence of sterility in this genotype class. When we ran our model that optimizes the effect sizes of each incompatibility to best explain hybrid male sterility, we found that the $C$. remanei $\mathrm{X}$-chromosome by $C$. latens autosome incompatibility is predicted to have a large effect on sterility, as well as a large influence of the $C$. latens $\mathrm{X}$ chromosome interacting with $C$. remanei autosomes (Table 2). We interpret this latter statistical result as the model successfully capturing the effect of the incompatibility involving the $C$. latens dominant $\mathrm{X}$ by $C$. remanei recessive autosomal region that causes inviability, and leads surviving males to have a greater than expected probability of being sterile. It is also likely that additional factors have a small influence on hybrid male sterility. Our full model identified two additional incompatibilities that reduce hybrid male fertility, but neither was significant (Table 2).

\section{DISCUSSION}

\section{Hybrid inviability is more genomically complex than hybrid sterility}

By quantifying postzygotic reproductive isolation between $C$. remanei and C. latens, we confirm that Haldane's rule holds true in this system, manifesting as strong asymmetric hybrid male sterility (Dey et al. 2014). We also found that the genetic basis of this hybrid male sterility can be almost fully explained by a two-factor incompatibility involving 
loci linked to the X-chromosome and autosomal chromosome, whereas hybrid inviability appears to be more genomically complex. Although our genomic resolution is coarse, we identify a minimum of three classes of incompatibilities that contribute to hybrid inviability: nuclearnuclear, mito-nuclear, and parental effects. Moreover, within the nuclear-nuclear class, our backcross results support roles of X-autosome, $\mathrm{X}-\mathrm{X}$, and autosome-autosome incompatibilities all as likely contributors to the hybrid incompatibilities causing inviability.

In our statistical model, we presumed that incompatibilities could only be either completely recessive or completely dominant, and we found support for both recessive and dominant incompatibilities contributing to hybrid inviability. However, given the multitude of potential loci involved in hybrid inviability and that both sexes contribute to our inference of embryonic and larval inviability, the true dominance coefficients for the hybrid incompatibility loci are unknown. This ambiguity has important implications, as a single partially dominant incompatibility could be interpreted as recessive-by-recessive, dominant-by-recessive, or both, depending on effect sizes, sex specificity, dominance coefficients, and statistical power. However, for a single incompatibility (e.g., $A_{\text {lat }}-A_{\text {rem }}$ ), our model rarely predicts that more than one of the possible dominance patterns leads to a reduction in fitness. In spite of this complication, we conclude that this issue does not appear too frequently in our analysis, though it implies that we may not accurately estimate the true minimum number of $G \times G$ incompatibilities involved in hybrid inviability. Although we now know that many incompatibilities must have at least a partially recessive component, as is true in other systems (Presgraves 2003; Tao and Hartl 2003; Masly and Presgraves 2007; Moyle and Nakazato 2008), more detailed estimation of the overall dominance requires finer resolution of incompatibility loci.

Despite this caveat, these results for Caenorhabditis differ strikingly from previous work in Drosophila (True et al. 1996; Hollocher and Wu 1996; Sawamura et al. 2000; Presgraves 2003; Tao et al. 2003) and Anopheles (Slotman et al. 2005), for which it is hybrid sterility that has a higher number of DMIs contributing to the phenotype than hybrid inviability. Superficially, our findings more closely mimic the low number of loci contributing to hybrid sterility observed in Solanum (Moyle and Nakazato 2008) and Tigriopus (Willett 2008). However, potential explanations for the distinction between Solanum/Tigriopus and Drosophila do not apply in Caenorhabditis. For example, both Drosophila and Caenorhabditis differ from Solanum/ Tigriopus in sex determination and reproductive biology (Solanum individuals are hermaphrodites, and both Solanum and Tigriopus lack sex chromosomes), which might influence the rate at which male reproductive traits accumulate incompatibilities such that Solanum/Tigriopus and similar systems would evolve hybrid male sterility with a lower number of DMIs contributing to the phenotype (Moyle and Graham 2005). What could explain the difference between flies and worms? One possibility is that incompatibilities localize to only particular loci in $\mathrm{Cae}$ norhabditis associated with a disruption of gonad morphogenesis. In Caenorhabditis, sperm-related genes have a faster rate of evolution than either oocyte or somatic genes (Cutter and Ward 2005; Artieri et al. 2008; Kasimatis and Phillips 2018). We, however, analyzed defects in the development of the somatic gonad and C. elegans genes expressed throughout male tissues have especially slow rates of protein evolution (Cutter and Ward 2005), suggesting that "faster male" theory might not apply in this case in a simple way (Wu and Davis 1993). Alternatively, and in contrast to the "fragile male" idea (Wu and Davis 1993), genetic networks that contain fast evolving genes (i.e., sperm genes) may be more tolerant of nucleotide substitutions and therefore less likely to be disrupted in hybrids, whereas slow evolving genes (e.g., other male expressed genes) may be more sensitive to disruption. This scenario could represent one way that male fertility traits and viability traits could differ in genetic architecture in terms of diminishing returns versus synergistic incompatibility effects (Guerrero et al. 2017).

Another possibility is that viability traits evolve disproportionately quickly in $C$. remanei and $C$. latens, and therefore accumulate more incompatibilities among the underlying loci. This relative slowdown of sexual trait versus viability trait evolution could happen, for example, if one or both of the species recently underwent adaptation to a novel environment, leading to disproportionate substitutions and incompatibilities associated with viability traits.

Finally, the relatively coarse scale of our experiments means that we cannot exclude the possibility that there may be many closely linked, but distinct, loci located on the $\mathrm{X}$ chromosome that contribute to hybrid male sterility to give the illusion of genetic simplicity in our backcross analysis. Consequently, our inference of the genetic complexity currently is restricted to the number of "genomic compartments" involved in incompatibilities. Understanding the total number of loci, DMI network degree of each incompatibility, and potential for antagonistic versus synergistic contributions of each DMI to reproductive isolation requires finer genetic resolution. Sperm-related and other reproduction-related genes do tend to cluster in the C. elegans genome (Miller et al. 2004), but sperm-enriched and germline-enriched genes are nearly absent from the $\mathrm{X}$ chromosome (Reinke et al. 2000, 2004). Further finemapping of reproductive isolation between $C$. remane $i$ and $C$. latens, and testing for possible additional contributors to hybrid male sterility beyond gonad defects, would help 
evaluate whether the apparently simple incompatibility for hybrid male sterility involves a single locus or multiple closely linked loci.

\section{Large-X effect}

We found that hybrid male sterility can be explained by an incompatibility involving an X-linked locus. Additionally, we created a model to determine how well the patterns of hybrid inviability seen in our $F_{1}$ and $F_{1}$ hybrid backcrosses could be explained by simple two-locus incompatibilities linked to either autosomal regions or to the X-chromosome (15 possible incompatibility types, Table 1 ). We found that to explain hybrid inviability with $\mathrm{G} \times \mathrm{G}$ incompatibilities, two of the three possible autosome-autosome, five of the eight autosome- $\mathrm{X}$, and two of the four possible $\mathrm{X}-\mathrm{X}$ incompatibilities must be invoked. Because the $\mathrm{X}$ chromosome represents only $20 \%$ of the genome, our results thus suggest an important role for X-linked incompatibilities both for asymmetric hybrid male sterility and for hybrid inviability. Our model predicts especially large magnitudes of effect on hybrids for X-linked incompatibilities as well (Table 1). This result points to a large- $\mathrm{X}$ effect in reproductive isolation between $C$. remanei and $C$. latens. Research on the other Caenorhabditis species pair that yields fertile hybrid offspring, $C$. nigoni and $C$. briggsae, also demonstrated an important role for X-linked loci in hybrid male inviability (Bi et al. 2015; Li et al. 2016), suggesting that a disproportionate influence of Xlinked loci could be a general pattern in Caenorhabditis nematodes as in other animals. The potential disruption of chromatin state on the $\mathrm{X}$-chromosome during male meiosis (meiotic sex chromosome inactivation), as implicated in the misregulation of $22 \mathrm{G}$ small RNAs in C. briggsae-nigoni hybrids ( $\mathrm{Li}$ et al. 2016), raises this possible mechanism for hybrid male sterility for $C$. remanei-latens hybrids.

\section{Higher-order incompatibilities}

There are multiple ways to define the complexity of the genetic architecture of reproductive isolation. Complexity of DMIs usually refers to the number of individual loci that make up a single incompatibility, its network size (Muller 1942). One could also consider complexity in other ways, for example, in terms of the total number of incompatibilities that contribute to overall reproductive isolation. We have considered complexity of interacting genomic compartments (autosome, X-chromosome, mitochondria, etc.) that contribute to overall reproductive isolation. In this study, presuming two-way DMIs between loci in distinct genomic compartments, we found that hybrid inviability between $C$. remanei and $C$. latens is "complex" in the sense that several two-way incompatibilities involving different genomic compartments are required to explain the observed hybrid inviability. But could a single three-way or four-way (or $n$-way) incompatibility explain the observed hybrid inviability? Multi-locus incompatibilities might be easier to evolve because there are more evolutionary trajectories from one genotype to another without passing through an unfit intermediate genotype (Cabot et al. 1994; Orr 1995). Additionally, multi-locus incompatibilities might be particularly common if the gene members of genetic pathways essential for development commonly experience rapid compensatory or coevolutionary trajectories, or if gene duplications or multigene family turnover contribute to multi-locus hybrid dysfunction. Numerous examples of multi-locus incompatibilities exist (Coyne and Orr 2004), and while this possibility is intriguing, it is difficult to test in our case. For example, while there are only 15 potential $\mathrm{G} \times$ $G$ incompatibility classes, there are 39 unique $G \times G \times G$ incompatibility classes revealed in offspring of backcrosses from $F_{1}$ hybrid individuals; our experiment has insufficient degrees of freedom to assess all possible contributions of $\mathrm{G} \times \mathrm{G} \times \mathrm{G}$ to the patterns of reproductive isolation. It is also possible that the $G \times G$ interactions we identified with our model are complex in that they could have epistatic interactions with each other, as is the case in Drosophila (Palopoli and Wu 1994; Chang et al. 2010) and Solanum (Guerrero et al. 2017). Future work in this system could attempt to further dissect the loci underlying hybrid inviability and sterility, which would provide valuable information about the number of genes underlying sterility and inviability, as well as the function of those genes. Promising possibilities for mapping include an evolve-and-resequence approach of hybrid populations (Gray and Cutter 2014; Long et al. 2015) and creation of Nearly Isogenic Lines or Recombinant Inbred Lines for performing quantitative trait locus mapping (e.g., Bradshaw and Schemske 2003; Moyle and Nakazato 2008; Guerrero et al. 2017) to more precisely determine the number and location of incompatibility loci between these species, as well as the interactions between individual DMI loci.

\section{Maternal effects on hybrid viability}

We determined that maternal effects contribute to hybrid inviability such that hybrid females produce zygotes with a lower hatch rate than do hybrid males, regardless of the genetic background of their mating partner. The mechanism by which this maternal-by-zygotic incompatibility manifests could derive from several different possible sources. One possibility could arise from the fact that, because males have only a single $\mathrm{X}$-chromosome, recombination between the $C$. latens and $C$. remanei $\mathrm{X}$-chromosomes only occurs in $\mathrm{F}_{1}$ females. Recombination in hybrid females involving inversion or rearrangement differences on the $\mathrm{X}$-chromosome 
could lead to gametes with gene duplications/deficiencies that render their offspring less competent to complete embryogenesis properly than zygotes derived from hybrid males with non-recombinant X-chromosomes. Such structural comparisons await characterization of the $C$. latens genome to contrast with $C$. remanei (Fierst et al. 2015).

Another possible source of maternal effects on hybrids could involve the provisioning of oocytes with maternal gene products. Dozens of maternal-effect gene mutants with consequences for embryogenesis have been identified in $C$. elegans (Kemphues et al. 1988; Hekimi et al. 1995). The function and specific effects for many of these genes have been well characterized (Evans 2005). For example, zyg-1 is a regulator of centrosome duplication, and the ZYG-1 protein kinase it encodes is required for daughter-cell centriole formation (O'Connell et al. 2001), such that mutations in zyg- 1 lead to nearly complete embryonic inviability (O'Connell et al. 1998). Other genes (e.g., pie-1 and mex-1 (Mello et al. 1992), rde-1 (Tabara et al. 1999), and clk-2 (Bénard et al. 2001)) have been similarly well characterized both for their function in wild-type $C$. elegans individuals and for the detrimental effects that mutations in these genes exert on embryonic development. Dysfunctional provisioning or activity of proteins like these by hybrid mothers to their oocytes provides one plausible source of maternalzygote incompatibility in interspecies hybrids. This could be caused either by functional divergence in the protein coding regions of such genes or by differences in regulatory control of them between the two species.

In addition to protein coding genes, many endogenous small RNAs control downstream gene expression in Caenorhabditis. Because many RNAs and proteins are maternally provisioned into the embryo (Evans 2005), the functional roles of these small RNAs may be disrupted in hybrid female germlines, their oocytes, or in zygotes. Before the zygote genome is activated, approximately $30 \%$ of the $\sim 7500$ genes expressed in the C. elegans oocyte are maternally targeted for degradation (Stoeckius et al. 2014). This targeting appears to be mediated by maternally encoded small interfering RNAs (Stoeckius et al. 2014), which in hybrid mothers may be mismatched from their mRNA target, leading to improper mRNA degradation in their embryos.

The Piwi-interacting RNA (piRNA) pathway has an evolutionarily conserved role in silencing exogenous sequences (e.g., transposons), as well as in properly expressing endogenous sequences in the germline (Ashe et al. 2012; Shirayama et al. 2012). The degree of silencing can vary depending on which parent encodes the silencing signal (Shirayama et al. 2012), and piRNA targeting can be sensitive to even a very small number of mismatches (Bagijn et al. 2012). This process is known to be disrupted in Drosophila hybrids (Kelleher et al. 2012), and could conceivably contribute to the hybrid embryonic inviability observed here as well. The many classes of small RNAs (microRNAs, 22G-RNA, 26G-RNA, and 21-U piRNAs) all have roles regulating gene expression that could get disrupted in hybrids (Grishok et al. 2001; Lau et al. 2001; Ambros et al. 2003; Malone and Hannon 2009), and small RNA misregulation is implicated in hybrid male sterility for C. briggsae-nigoni hybrids ( $\mathrm{Li}$ et al. 2016). Comparing small RNA expression in embryos produced by hybrid females with the RNA expression in embryos produced by hybrid males and pure species would be a first step to test this hypothesis for why hybrid females produce inviable embryos more often than do hybrid males.

\section{Conclusion}

We have quantified inviability and male sterility in $C$. remanei $\times C$. latens hybrids. We found that hybrid male sterility can be mostly explained by a simple two-factor Xautosome incompatibility, whereas hybrid inviability is more genomically complex by involving multiple combinations of genomic compartments in reproductive isolation, including autosome-autosome, $\mathrm{X}$-autosome, $\mathrm{X}$-X, and mitonuclear interactions. We anticipate that future work with Caenorhabditis will continue to refine the genetic causes Haldane's rule, asymmetric reproductive isolation, the large-X effect, and faster male evolution.

\section{Data archiving}

Data are available from the Dryad Digital Repository:

https://datadryad.org//resource/doi:10.5061/dryad. $3571 \mathrm{q} 4 \mathrm{t}$

Acknowledgements We thank Daven Presgraves for comments on this manuscript. Funding was provided by a Natural Sciences and Engineering Research Council of Canada Discovery Grant to ADC, and by an Ontario Graduate Scholarship to JDB.

\section{Compliance with ethical standards}

Conflict of interest The authors declare that they have no conflict of interest.

\section{References}

Ambros V, Lee RC, Lavanway A, Williams PT, Jewell D (2003) MicroRNAs and other tiny endogenous RNAs in C. elegans. Curr Biol 13:807-818

Artieri CG, Haerty W, Gupta BP, Singh RS (2008) Sexual selection and maintenance of sex: evidence from comparisons of rates of genomic accumulation of mutations and divergence of sex-related genes in sexual and hermaphroditic species of Caenorhabditis. Mol Biol Evol 25:972-979 
Ashe A, Sapetschnig A, Weick E-M, Mitchell J, Bagijn MP, Cording AC et al. (2012) piRNAs can trigger a multigenerational epigenetic memory in the germline of C. elegans. Cell 150:88-99

Bagijn MP, Goldstein LD, Sapetschnig A, Weick E-M, Bouasker S, Lehrbach NJ et al. (2012) Function, targets, and evolution of Caenorhabditis elegans piRNAs. Science 337:574-578

Bates D, Maechler M, Bolker BM, Walker SC (2015) Fitting linear mixed-effects models using lme4. J Stat Softw 67:1-48

Bateson W (1909) Heredity and variation in modern lights. In: Seward AC (ed) Darwin and modern science. Cambridge Univ. Press, Cambridge, $p$ 85-101

Bénard C, McCright B, Zhang Y, Felkai S, Lakowski B, Hekimi S (2001) The C. elegans maternal-effect gene $c l k-2$ is essential for embryonic development, encodes a protein homologous to yeast Tel2p and affects telomere length. Development 128:4045-4055

Bi Y, Ren X, Yan C, Shao J, Xie D, Zhao Z (2015) A genome-wide hybrid incompatibility landscape between Caenorhabditis briggsae and C. nigoni. PLoS Genet 11:e1004993

Bolnick DI, Near TJ, Noor M (2005) Tempo of hybrid inviability in centrarchid fishes (Teleostei: Centrarchidae). Evolution 59:1754-1767

Bradshaw HD, Schemske DW (2003) Allele substitution at a flower colour locus produces a pollinator shift in monkeyflowers. Nature 426:176-178

Breeuwer J, Werren JH (1995) Hybrid breakdown between two haplodiploid species: the role of nuclear and cytoplasmic genes. Evolution 49:705-717

Burton RS (1990) Hybrid breakdown in developmental time in the copepod Tigriopus californicus. Evolution 44:1814-1822

Cabot EL, Davis AW, Johnson NA, Wu CI (1994) Genetics of reproductive isolation in the Drosophila simulans clade: complex epistasis underlying hybrid male sterility. Genetics 137:175-189

Chang AS, Bennett SM, Noor MAF (2010) Epistasis among Drosophila persimilis factors conferring hybrid male sterility with $D$. pseudoobscura bogotana. PLoS ONE 5:e15377-5

Coyne JA (1985) The genetic basis of Haldane's rule. Nature 314:736-738

Coyne JA (1992) Genetics and speciation. Nature 355:511-515

Coyne JA, Orr HA (1989) Patterns of speciation in Drosophila. Evolution 43:362-381

Coyne JA, Orr HA (2004) Speciation. Sinauer Associates Inc., Sunderland, Massachusetts

Cutter AD (2015) Caenorhabditis evolution in the wild. Bioessays 37:983-995

Cutter AD, Ward S (2005) Sexual and temporal dynamics of molecular evolution in C. elegans development. Mol Biol Evol 22:178-188

Denver DR, Dolan PC, Wilhelm LJ, Sung W, Lucas-Lledo JI, Howe DK et al. (2009) A genome-wide view of Caenorhabditis elegans base-substitution mutation processes. Proc Natl Acad Sci USA 106:16310-16314

Dettman JR, Jacobson DJ, Turner E, Pringle A, Taylor JW (2003) Reproductive isolation and phylogenetic divergence in Neurospora: comparing methods of species recognition in a model eukaryote. Evolution 57:2721-2741

Dey A, Jeon Y, Wang G-X, Cutter AD (2012) Global population genetic structure of Caenorhabditis remanei reveals incipient speciation. Genetics 191:1257-1269

Dey A, Jin Q, Chen Y-C, Cutter AD (2014) Gonad morphogenesis defects drive hybrid male sterility in asymmetric hybrid breakdown of Caenorhabditis nematodes. Evol Dev 16:362-372

Dobzhansky T (1937) Genetics and the Origin of Species. Columbia Univ. Press, New York, New York

Evans, TC, CP Hunter (2005) Translational control of maternal RNAs. In: The C. elegans Research Community (eds) WormBook. https://doi.org/10.1895/wormbook.1.34.1
Félix M-A, Braendle C, Cutter AD (2014) A streamlined system for species diagnosis in Caenorhabditis (nematoda: rhabditidae) with name designations for 15 distinct biological species. PLoS ONE 9:e94723

Fierst JL, Willis JH, Thomas CG, Wang W, Reynolds RM, Ahearne TE et al. (2015) Reproductive mode and the evolution of genome size and structure in Caenorhabditis nematodes. PLoS Genet 11: e1005323-25

Good JM, Handel MA, Nachman MW (2008) Asymmetry and polymorphism of hybrid male sterility during the early stages of speciation in house mice. Evolution 62:50-65

Gray JC, Cutter AD (2014) Mainstreaming Caenorhabditis elegans in experimental evolution. Proc R Soc Biol Sci Ser B 281:20133055

Grishok A, Pasquinelli AE, Conte D, Li N, Parrish S, Ha I et al. (2001) Genes and mechanisms related to RNA interference regulate expression of the small temporal RNAs that control C. elegans developmental timing. Cell 106:23-34

Guerrero RF, Muir CD, Josway S, Moyle LC (2017) Pervasive antagonistic interactions among hybrid incompatibility loci. PLoS Genet 13:e1006817-19

Hekimi S, Boutis P, Lakowski B (1995) Viable maternal-effect mutations that affect the development of the nematode Caenorhabditis elegans. Genetics 141:1351-1364

Hollocher H, Wu CI (1996) The genetics of reproductive isolation in the Drosophila simulans clade: $\mathrm{X}$ vs. autosomal effects and male vs. female effects. Genetics 143:1243-1255

Kalirad A, Azevedo RBR (2017) Spiraling Complexity: a test of the snowball effect in a computational model of RNA folding. Genetics 206:377-388

Kasimatis KR, Phillips PC (2018) Rapid gene family evolution of a nematode sperm protein despite sequence hyper-conservation. G3 8:353-362

Kelleher ES, Edelman NB, Barbash DA (2012) Drosophila interspecific hybrids phenocopy piRNA-pathway mutants. PLoS Biol 10:e1001428-18

Kemphues KJ, Priess JR, Morton DG, Cheng NS (1988) Identification of genes required for cytoplasmic localization in early C. elegans embryos. Cell 52:311-320

Lau NC, Lim LP, Weinstein EG, Bartel DP (2001) An abundant class of tiny RNAs with probable regulatory roles in Caenorhabditis elegans. Science 294:858-862

Li R, Ren X, Bi Y, Ho VWS, Hsieh C-L, Young A et al. (2016) Specific down-regulation of spermatogenesis genes targeted by $22 \mathrm{G}$ RNAs in hybrid sterile males associated with an Xchromosome introgression. Genome Res 26:1219-1232

Li Z, Pinson SR, Paterson AH, Park WD, Stansel JW (1997) Genetics of hybrid sterility and hybrid breakdown in an intersubspecific rice (Oryza sativaL.) population. Genetics 145:1139-1148

Long A, Liti G, Luptak A, Tenaillon O (2015) Elucidating the molecular architecture of adaptation via evolve and resequence experiments. Nat Rev Genet 16:567-582

Malone CD, Hannon GJ (2009) Small RNAs as guardians of the genome. Cell 136:656-668

Masly JP, Presgraves DC (2007) High-resolution genome-wide dissection of the two rules of speciation in Drosophila. PLoS Biol 5: e243

Mello CC, Draper BW, Krause M, Weintraub H (1992) The pie-1 and mex-1 genes and maternal control of blastomere identity in early C. elegans embryos. Cell 70:163-176

Miller MA, Cutter AD, Yamamoto I, Ward S, Greenstein D (2004) Clustered organization of reproductive genes in the C. elegans genome. Curr Biol 14:1284-1290

Moyle LC, Graham EB (2005) Genetics of hybrid incompatibility between Lycopersicon esculentum and L. hirsutum. Genetics 169:355-373 
Moyle LC, Nakazato T (2008) Comparative genetics of hybrid incompatibility: sterility in two Solanum species crosses. Genetics 179:1437-1453

Moyle LC, Olson MS, Tiffin P (2004) Patterns of reproductive isolation in three angiosperm genera. Evolution 58:1195-1208

Muller HJ (1942) Isolating mechanisms, evolution and temperature. Biol Symp 6:71-125

O'Connell KF, Caron C, Kopish KR, Hurd DD (2001) The C. elegans $z y g-1$ gene encodes a regulator of centrosome duplication with distinct maternal and paternal roles in the embryo. Cell 105:547-558

O'Connell KF, Leys CM, White JG (1998) A genetic screen for temperature-sensitive cell-division mutants of Caenorhabditis elegans. Genetics 149:1303-1321

Oka A, Mita A, Sakurai-Yamatani N, Yamamoto H, Takagi N, Takano-Shimizu T et al. (2004) Hybrid breakdown caused by substitution of the $\mathrm{X}$ chromosome between two mouse subspecies. Genetics 166:913-924

Orr HA (1995) The population-genetics of speciation-the evolution of hybrid incompatibilities. Genetics 139:1805-1813

Orr HA (1999) Does hybrid lethality depend on sex or genotype? Genetics 152:1767-1769

Orr HA, Turelli M (2001) The evolution of postzygotic isolation: accumulating Dobzhansky-Muller incompatibilities. Evolution 55:1085-1094

Palopoli MF, Wu CI (1994) Genetics of hybrid male sterility between Drosophila sibling species: a complex web of epistasis is revealed in interspecific studies. Genetics 138:329-341

Presgraves DC (2002) Patterns of postzygotic isolation in Lepidoptera. Evolution 56:1168-1183

Presgraves DC (2003) A fine-scale genetic analysis of hybrid incompatibilities in Drosophila. Genetics 163:955-972

Presgraves DC (2008) Sex chromosomes and speciation in Drosophila. Trends Genet 24:336-343

Presgraves DC (2010) Darwin and the origin of interspecific genetic incompatibilities. Am Nat 176(Suppl 1):S45-60

Price TD, Bouvier MM (2002) The evolution of F1 postzygotic incompatibilities in birds. Evolution 56:2083-2089

R Core Team (2016) R: A language and environment for statistical computing. www.R-project.org

Ramsey J, Bradshaw HD, Schemske DW (2003) Components of reproductive isolation between the monkeyflowers Mimulus lewisii and M. cardinalis (Phrymaceae). Evolution 57:1520-1534

Reinke V, Gil IS, Ward S, Kazmer K (2004) Genome-wide germlineenriched and sex-biased expression profiles in Caenorhabditis elegans. Development 131:311-323

Reinke V, Smith HE, Nance J, Wang J, Van Doren C, Begley R et al. (2000) A global profile of germline gene expression in C. elegans. Mol Cell 6:605-616

Sawamura K, Davis AW, Wu CI (2000) Genetic analysis of speciation by means of introgression into Drosophila melanogaster. Proc Natl Acad Sci USA 97:2652-2655
Schluter D (1998) Ecological causes of speciation. In: Howard DJ, Berlocher SH (eds) Endless forms: species and speciation. Oxford Univ. Press, New York, p 114-129

Scopece G, Musacchio A, Widmer A, Cozzolino S (2007) Patterns of reproductive isolation in Mediterranean deceptive orchids. Evolution 61:2623-2642

Shirayama M, Seth M, Lee H-C, Gu W, Ishidate T, Conte D et al. (2012) piRNAs initiate an epigenetic memory of nonself RNA in the C. elegans germline. Cell 150:65-77

Slotman M, Torre Della A, Powell JR, Noor M (2005) Female sterility in hybrids between Anopheles gambiae and A. arabiensis, and the causes of Haldane's rule. Evolution 59:1016-1026

Stiernagle T (1999) Maintenance of C. elegans. In: Hope IA (ed.) C. elegans: a practical approach. Oxford Univ. Press, New York, p 51-67

Stoeckius M, Grün D, Kirchner M, Ayoub S, Torti F, Piano F et al. (2014) Global characterization of the oocyte-to-embryo transition in Caenorhabditis elegans uncovers a novel mRNA clearance mechanism. EMBO J 33:1751-1766

Tabara H, Sarkissian M, Kelly WG, Fleenor J, Grishok A, Timmons L et al. (1999) The rde-1 gene, RNA interference, and transposon silencing in C. elegans. Cell 99:123-132

Tao Y, Hartl DL (2003) Genetic dissection of hybrid incompatibilities between Drosophila simulans and D. mauritiana. III. Heterogeneous accumulation of hybrid incompatibilities, degree of dominance, and implications for Haldane's rule. Evolution 57:2580-2598

Tao Y, Chen S, Hartl DL, Laurie CC (2003) Genetic dissection of hybrid incompatibilities between Drosophila simulans and $D$. mauritiana. I. Differential accumulation of hybrid male sterility effects on the X and autosomes. Genetics 164:1383-1397

True JR, Weir BS, Laurie CC (1996) A genome-wide survey of hybrid incompatibility factors by the introgression of marked segments of Drosophila mauritiana chromosomes into Drosophila simulans. Genetics 142:819-837

Turelli M, Moyle LC (2007) Asymmetric postmating isolation: Darwin's corollary to Haldane's rule. Genetics 176:1059-1088

Turissini DA, McGirr JA, Patel SS, David JR, Matute DR (2017) The rate of evolution of postmating-prezygotic reproductive isolation in Drosophila Mol Biol Evol 35:1-23

Willett CS (2008) No evidence for faster male hybrid sterility in population crosses of an intertidal copepod (Tigriopus californicus). Genetica 133:129-136

Woodruff GC, Eke O, Baird SE, Felix MA, Haag ES (2010) Insights into species divergence and the evolution of hermaphroditism from fertile interspecies hybrids of Caenorhabditis nematodes. Genetics 186:997-1012

Wu CI (1992) A note on Haldane's rule: hybrid inviability versus hybrid sterility. Evolution 46:1584-1587

Wu CI, Davis AW (1993) Evolution of postmating reproductive isolation: the composite nature of Haldane's rule and its genetic bases. Am Nat 142:187-212 